\section{Advanced Inorganic Materials for Photovoltaics}

\section{Abdelilah Slaoui and Reuben T. Collins, Guest Editors}

\begin{abstract}
By 2050, world annual energy consumption is predicted to grow from the present 13 terawatt-years (TWyr) to nearly 30 TWyr. Although all energy sources must be considered in meeting this challenge, solar energy may arguably be the only carbonfree source capable of supplying a significant fraction of energy at these levels. This issue of MRS Bulletin reviews the status and future development of solar photovoltaic technologies based on inorganic materials. The discussion begins with materials and cell designs for second-generation photovoltaics based on thin films [a-Si: $\mathrm{H}, \mathrm{Si}$, $\mathrm{Cu}(\mathrm{In}, \mathrm{Ga})(\mathrm{Se}, \mathrm{S})_{2}$, CdTe]. Recent advances in tandem cells and concentrators are also reported, along with photovoltaic approaches involving nanoscale materials such as quantum dot arrays. Finally, work on transparent conducting oxides that are critical to nearly all cell designs are discussed.
\end{abstract}

\section{Photovoltaic Market}

World annual energy consumption is predicted to grow from the current 13 terawattyears (TWyr) to as much as 30 TWyr by 2050. ${ }^{1}$ As we struggle to meet this huge demand, the global energy sector will also face two pressing issues: declining fossil reserves and climate change caused by artificially produced greenhouse gas emissions.

Nuclear power is considered a leading candidate for reduced-carbon-emission electricity production. There is, however, uncertainty about the size of nuclear fuel reserves, the efficiency of nuclear reactors when using lower-grade uranium ores, and the likelihood of finding satisfactory solutions for nuclear waste disposal. Estimates by the International Atomic Energy Agency indicate that nuclear power growth will flatten in coming years. ${ }^{2}$

In terms of renewable sources, hydroelectric power is one of the dominant technologies today, but supply expansion is limited.

Wind power is approaching competitiveness with conventional power production and must be considered as an important source in meeting future energy needs. Some estimates, however, place the total usable wind energy production in the 2-4 TWyr range, much less than the 30 TWyr level.

With roughly 125,000 TW of solar power striking the earth at any time, solar may be the only renewable energy source with the capacity to meet a large fraction of future needs.

There are many different approaches for capturing solar energy. ${ }^{1}$ Photosynthetic solar conversion for biofuel production is under active investigation. Solar thermal systems convert the sun's radiation into thermal energy for heating applications or, in conjunction with solar concentration, into electricity.

This article deals with photovoltaic (PV) electricity generation, and the key issue is cost. Assuming a 20-yr system lifetime, the present cost of PV-generated electricity is in the range of $\$ 0.25-\$ 0.65 / \mathrm{kWh}$, as compared with the cost of coal-based electricity, which is closer to $\$ 0.04 / \mathrm{kWh}^{3}$

Generating a significant fraction of future energy requirements from PVs is a major challenge, particularly because present PV production is almost insignificant relative to fossil-fuel-based generation. In 2003 in the United States, solar energy produced $\sim 0.1 \%$ of the electricity generated by fossil fuels. At the same time, PV costs have reached a range where demand is very elastic, with small decreases in price causing large increases in sales. As a consequence, PV manufacturing is growing exponentially at approximately $30 \%$ per year, and this rate is, if anything, increasing (Figure 1). In 2005, the PV market exceeded $\$ 10$ billion. ${ }^{4}$ This growth has been driven by government policies (subsidies or feed-in tariffs), mainly in Japan and in Germany. ${ }^{5}$ PV production will be further stimulated by the PV goals for Europe of supplying 12\% of total energy and $22 \%$ of electricity from renewable sources in 2010.6,7 Similarly, the Solar America Initiative in the United States calls for investments to make PV power competitive with other forms of renewable energy by $2015,{ }^{8}$ and more than 15 U.S. states have mandated renewable energy standards.

This market growth will drive price reductions. The historic learning curve for PV module manufacturing shows a $20 \%$ price reduction for every doubling of accumulated sales through about 2003 (see Figure 2). The price of standard PV modules, typically expressed in units of cost divided by the power produced under peak solar illumination (in watts), is currently around $\$ 3-\$ 4 / \mathrm{Wp}$. Taking into account PV system costs that are not related to the solar panel raises the price to about $\$ 6-\$ 8 / W p$, which converts to roughly the $\$ 0.25-\$ 0.65 / \mathrm{kWh}$ range given earlier. Assuming a $25 \%-30 \%$ per year market growth, the learning curve yields a factor of two drop in cost every 8-10 years. Reaching a competitive cost with current coal-produced electricity would take 30-40 years. Although this extrapolation is strongly dependent on market growth and learning curve assumptions, as well as future prices of conventional electricity, most estimates give similar time frames. If these estimates prove true, PVs will have a limited ability to make significant contributions to 2050 energy needs.

The learning curve derives primarily from wafer-based crystalline silicon (monocrystalline or single-crystal, multicrystalline, and some ribbon silicon) modules that dominate the PV market, comprising more than $90 \%$ of shipments in 2005 (Figure 3). This is typically referred to as the first generation of photovoltaics. The dominance of crystalline silicon stems from its wide availability and reliability, as well as from knowledge and technology borrowed from the microelectronics industry and resulting from more than two decades of terrestrial PV research with substantial government funding. The price reductions already achieved with silicon are significant (Figure 2). Although the shortage in silicon 
feedstock that is currently influencing the learning curve (Figure 2) is likely to be resolved in the near future, there are still questions about whether the present curve can be maintained with silicon. ${ }^{9}$ The movement toward thinner silicon wafers and the future development of higherefficiency cells will certainly help. Even if this trend is maintained, a discontinuity in the learning curve is needed for the 30-40-year time frame discussed here to be reduced.

It is a common belief that lowering PV costs to a level competitive with conventional power sources will require significant reductions in manufacturing costs, which may be realized in thin films, and/or new architectures that lead to dramatic improvements in efficiency. ${ }^{10}$ Indeed, once in large-volume production,

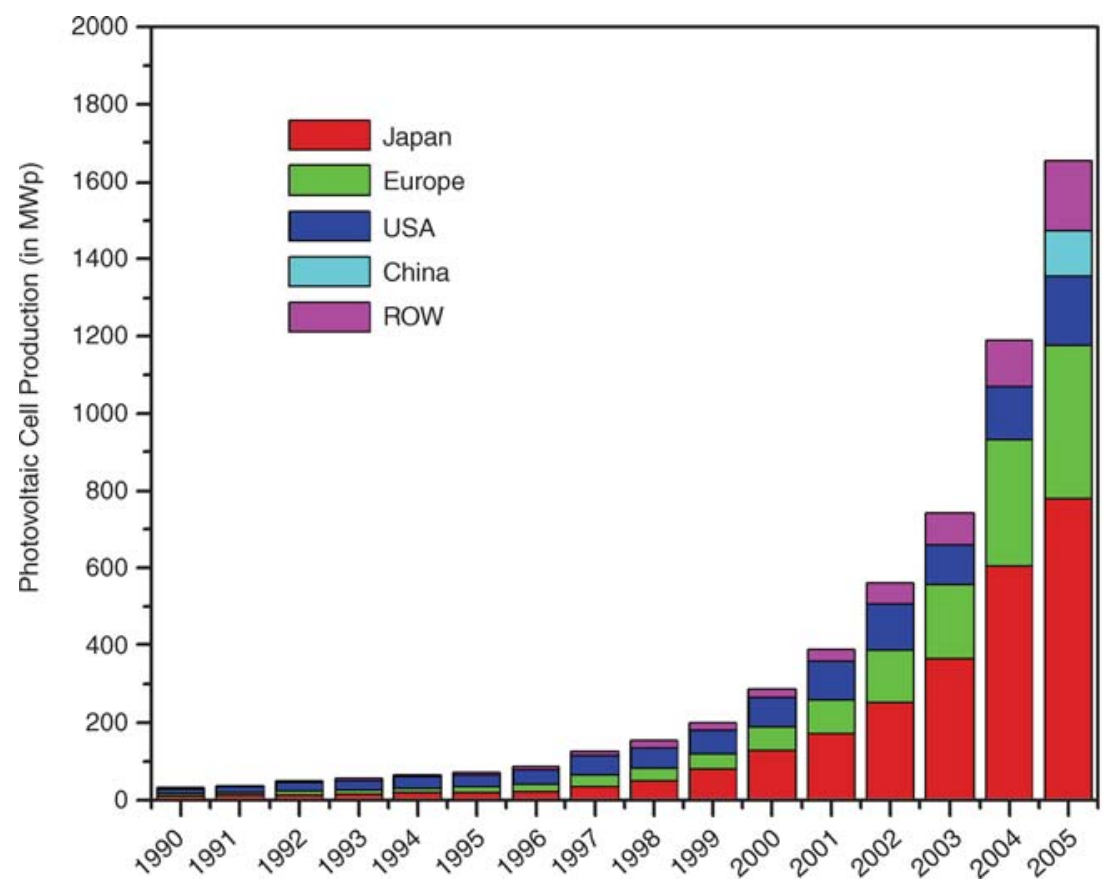

Figure 1. Photovoltaic cell production in peak megawatts (MWp) as reported by the PV industry. Shipments for Japan, Europe, the United States, China, and the rest of the world (ROW) are shown. (Source: PV News, Photon International, and the IEA Photovoltaic Power Systems Program.)

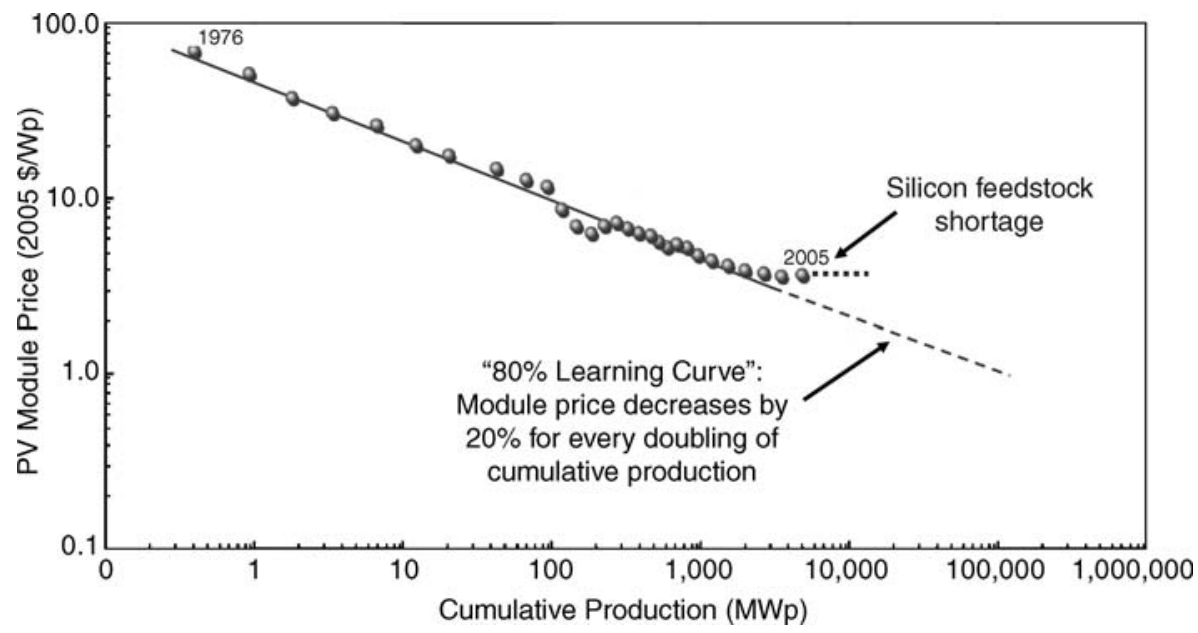

Figure 2. Photovoltaic module prices per peak watt $(\mathrm{Wp})$ against cumulative production in peak megawatts (MWp). (After T. Surek, National Renewable Energy Laboratory, 2007).

second-generation cells based on thin films will offer the potential for appreciably lower areal manufacturing costs with reasonable efficiencies.

On the other hand, third-generation concepts attempt to exploit a much larger fraction of the solar spectrum to achieve very high efficiencies while also lowering costs.

Second- and third-generation inorganic PV technologies are the principal subject of this issue of MRS Bulletin. Although not discussed in detail here, organic solar cells also have significant potential for low-cost energy production, and the interested reader is referred to the January 2005 MRS Bulletin for an in-depth review of these technologies. ${ }^{11}$

\section{Photovoltaic Devices}

A solar cell is a semiconductor device that converts photons from the sun into electricity. Figure 4 shows the generic structure and operation of a single-junction inorganic solar cell. The highest efficiency devices (e.g., single-crystal Si) are made on crystalline substrates. This is an important contributor to system costs, which secondgeneration approaches seek to reduce through thin-film techniques compatible with low-cost substrates like glass. At the heart of the cell is the light-absorbing material that converts photons into carriers (electrons and holes) via the photovoltaic effect. The different PV technologies discussed in this issue are identified by the composition of the absorbing material. After

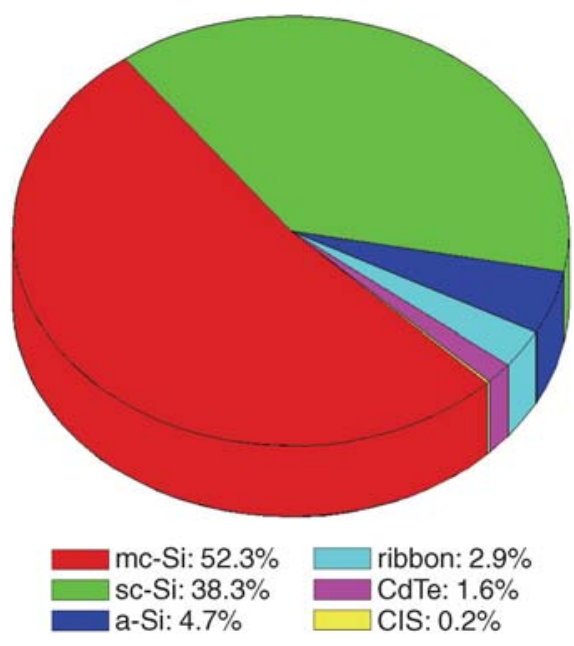

Figure 3. Distribution of photovoltaic cell production by technology in 2006 : multicrystalline Si (mc-Si), single-crystal $\mathrm{Si}$ (sc-Si), amorphous $\mathrm{Si}(\mathrm{a}-\mathrm{Si}$ ), ribbon $\mathrm{Si}, \mathrm{CdTe}$, and copper indium diselenide (CIS). [Source: Photon International (March 2006).] 


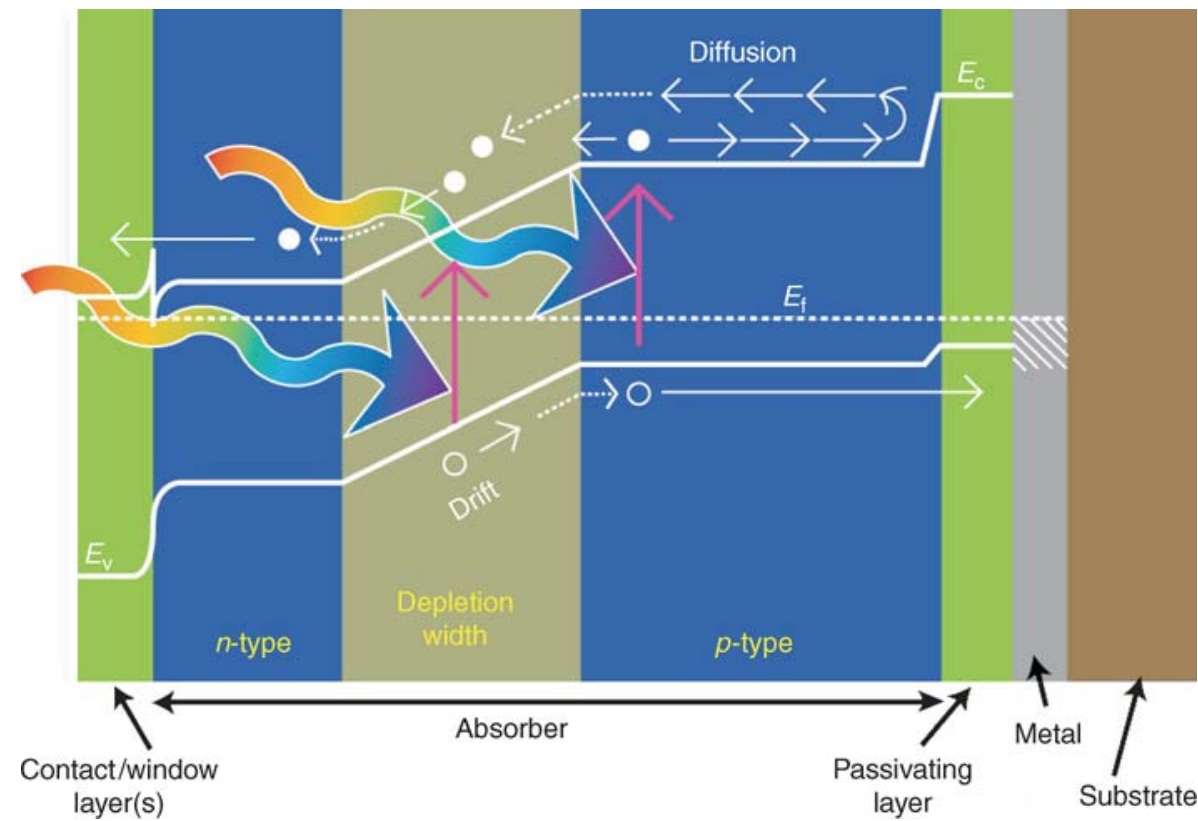

Figure 4. Schematic illustration of a $p-n$ junction solar cell, showing the structure, carrier generation, and separation. Wavy arrows represent photons. $E_{v}$ is the valence-band energy, $E_{\mathrm{f}}$ is the Fermi level, and $E_{\mathrm{c}}$ is the conduction-band energy. (Courtesy of S. Kurtz.)

carrier generation, the electrons and holes separate and are collected at the contacts. There are two main modes for charge carrier separation: drift of carriers, driven by the built-in electrostatic field of a $p-n$ junction, and diffusion of carriers from zones of high to low carrier concentration following an electrochemical potential gradient. These are illustrated in Figure 4. When drift is important, the structure of the cell (e.g., the depletion width) can be used to compensate for poor diffusion. When diffusion is dominant, optimizing materials quality becomes more important. Drift is typical of inorganic cells, which are normally $p-n$ junction devices. The highest-efficiency devices, however, rely on diffusion to transport carriers to the junction for collection. Diffusion is the dominant transport mechanism for dye or organic solar cells.

The properties of the contacts and window layers are also critical to device performance. At least one contact must be electrically conducting and transparent to photons in the spectral range where the absorber creates carriers. Transparent conducting oxides are the material of choice for this purpose. It is also important to point out that the simple structure and the division into well-defined layers with specific functions shown in Figure 4 are not adequate to describe many solar cells. In a number of designs, light enters through the substrate, and contacts can be quite complicated, fabricated from several layers with significant interdiffusion at metallurgical junctions.

\section{Photovoltaic Figures of Merit}

Some of the basic metrics for characterizing PV devices will appear in the articles in this issue. Figure 5 shows a typical current-voltage characteristic of a solar cell in the dark and under illumination. Power is generated when the cell operates in the fourth quadrant of the graph where voltage is positive and current is negative. The fill factor is the power produced at the maximum power point on the illuminated $J-V$ curve divided by the product of the open-circuit voltage $\left(V_{\text {oc }}\right)$ and short-circuit current $\left(J_{\text {sc }}\right)$. Think of it as a measure of how rectangular the $J-V$ characteristic is in the fourth quadrant. Another useful measure, quantum efficiency $(\mathrm{QE})$, is the ratio of the number of charge carriers collected by the solar cell to the number of photons at a given illuminating energy. Ideally, it is a step function at the bandgap of the absorber. In real devices, however, the absorption threshold is less abrupt ${ }^{12}$ - the step is sloped instead of vertical-and there is also a roll-off at higher energies.

The most fundamental measure of performance is, of course, the energy conversion efficiency-the percentage of power converted from sunlight to electrical energy. Two decades ago, Shockley and Queisser ${ }^{13}$ used a detailed-balance approach to estimate the thermodynamic efficiency limit for solar cells with a single absorbing

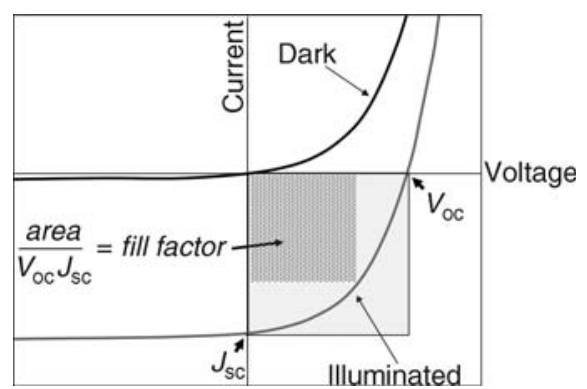

Figure 5. Current-voltage $(\mathrm{J}-\mathrm{V})$ characteristic of a solar cell with and without illumination. The open-circuit voltage $\left(V_{\text {oc }}\right)$, short-circuit current $\left(J_{\mathrm{sc}}\right)$, and fill factor are identified.

material (single junction). Their approach balanced the radiative transfer between the sun, modeled as a black body at $6000 \mathrm{~K}$ and the solar cell, assumed to be a $300 \mathrm{~K}$ black body, which absorbs photons with energy above an energy threshold (the bandgap). They varied the bandgap of the absorber and the solid angle from which the solar cell can collect the sun's radiation (concentration). As the bandgap of the absorber is increased, the open-circuit voltage increases, but because only photons with energy above the bandgap are converted into carriers, the short-circuit current decreases. This tradeoff between voltage and current leads to a maximum in efficiency as a function of bandgap. For unconcentrated solar irradiance (one sun), a maximum efficiency limit of $\sim 31 \%$ at a gap near $1.3 \mathrm{eV}$ was found. For full solar concentration $(46,300$ suns), maximum efficiency was $\sim 41 \%$ for a $1.1 \mathrm{eV}$ material.

\section{Improving the Cost Performance of PV Devices}

The record unconcentrated efficiencies for single-crystal Si (sc-Si) cells and modules are $24.7 \%$ and $22.7 \%$, respectively. For multicrystalline $\mathrm{Si}(\mathrm{mc}-\mathrm{Si})$, the best efficiencies are $20.3 \%$ and $15.3 \%$, respectively. ${ }^{14}$ These values are far enough below the theoretical limit that there is still room for efficiency improvements; hence, laboratory and industrial-scale efforts focus on improving cell efficiencies and also on implementing innovative and low-cost fabrication processes. Whereas wafer-based Si solar cells dominate the market and are likely to maintain this dominance in the near future, approaches with the potential for much more significant solar electricity cost reductions are needed if PVs are to contribute substantially to future energy needs. In this issue of MRS Bulletin, we have chosen to focus on second-and thirdgeneration approaches with the potential for achieving significant cost reductions. 
For a review of the status of crystalline and mc-Si photovoltaic technology, interested readers are referred to Reference 15.

In the simplest view, the cost of PVgenerated electricity is set by a tradeoff between manufacturing cost, system lifetime, and solar conversion efficiency. Secondgeneration approaches focus on reduced manufacturing cost using thin-film techniques to lower substrate costs, materials usage, and processing expense. The first two articles in this issue, by Schropp et al. and Beach and McCandless, describe recent activities in polycrystalline/ amorphous silicon solar cells and in chalcogenide-based thin-film PVs. Despite the remarkable progress these technologies have made in the last years, the actual market share of thin-film technologies is very modest ( $<7 \%$ total for CIS, CdTe, and a-Si; see Figure 3). In part, this is because processes and equipment for manufacturing thin-film modules are less mature than for crystalline silicon. There is considerable room for materials, energy utilization, and process optimization. This drives a strong need for basic materials research, especially as it relates to lower manufacturing costs with improved reliability and module efficiency.

Third-generation technologies attempt to "leapfrog" to a cost-efficiency performance competitive with conventional electricity production. They are sometimes defined as approaches that do not rely on conventional $p-n$ junctions. Organic and dye-sensitized solar cells are examples. A more formal definition involves cells capable of higher efficiency then the singlejunction Shockley-Queisser limit. Using this definition, the next two articles, by Dimroth and Kurtz and by Luque et al., discuss third-generation PV approaches, such as multijunction and quantum dot solar cells. Returning to the efficiency discussion, from a purely thermodynamic argument, the maximum solar conversion efficiency for the sun at $6000 \mathrm{~K}$ and a solar conversion device at $300 \mathrm{~K}$ follows from the Carnot efficiency and is about 95\%. The much lower single-junction ShockleyQueisser limit of roughly $\sim 30 \%$ arises from two fundamental loss mechanisms: transmission loss of photons with energies below the bandgap, and thermal relaxation of hot carriers created by photons with energies greater than the bandgap.

Tandem or multijunction approaches are discussed first by Dimroth and Kurtz. They integrate multiple absorbers with different bandgaps into the same cell. A broader portion of the solar spectrum is absorbed while minimizing thermal relaxation losses. Tandem solar cells based on III-V compound semiconductors are a relatively mature technology used extensively in space power applications where the power-to-weight ratio is the key figure of merit. They have the highest reported efficiencies but are fabricated on singlecrystal substrates using epitaxial deposition techniques and, hence, are relatively expensive to manufacture. Generating lowcost electricity with these devices requires solar concentration to reduce the required cell area. Research and development in this field is focused on increasing the efficiency from $40 \%$ to $50 \%$ and on reducing manufacturing cost while optimizing the cells for specific applications.

In their article, Luque et al. discuss a more speculative approach toward very high efficiencies based on nanotechnology. Quantum-dot-based cells have a theoretical thermodynamic conversion efficiency of up to $\sim 66 \%$ under high concentration, similar to that of a three-junction cell. In particular, approaches based on multiple exciton generation (two or three excitons generated per incident photon) mitigate the losses associated with thermalization of carriers created by above-bandgap absorption, whereas intermediate-band solar cells focus on capturing energy from subbandgap photons.

The final article, by Fortunato et al., is devoted to an important class of inorganic materials found in nearly every thin-film PV device, namely, transparent conducting oxides (TCOs). TCOs function simultaneously as a window layer, enabling light to reach the active absorbing material, and as an ohmic contact, transporting photogenerated charge carriers away from the absorber. Indium-oxide-based films are presently the dominant TCO. The high cost of In, coupled with the growing realization that the properties required of TCOs are dependent on the PV technology under consideration, is driving research into alternative materials and processes tailored to specific applications. The article reviews TCOs in current use, the requirements that present and future PV technologies place on TCOs, and research directions designed to meet these needs.

\section{Summary}

Photovoltaic technology holds the promise of an almost inexhaustible energy source with minimal environmental impact. Significant reductions in the cost of PV-produced power are required to realize this potential, and the inorganic PV technologies reviewed in this issue are focused on meeting this challenge. In the simplest view, all PV devices perform the same two functions: conversion of photons into carriers and collection of those carriers. In addition, the research directions pursued in each technology have the same ultimate goals of reduced manufacturing cost and increased conversion efficiency. In reality, the rich set of materials issues that must be resolved to achieve these goals vary significantly from one materials system to the next. The ability of researchers in this field to identify and overcome the challenges associated with each technology will determine which are successful in making it to the marketplace and ultimately whether PVs are successful in realizing their promise.

\section{Acknowledgments}

A. Slaoui gratefully acknowledges valuable discussions with J.C. Muller and financial support from Centre National de la Recherche Scientifique (France), Agence de la Maitrise de l'Energie (ADEME), and Agence Nationale de la Recherche (ANR-PV). R.T. Collins is also grateful for valuable discussions with Arthur Nozik, Sarah Kurtz, Tom Surek, and Joseph Beach, and financial support from the $\mathrm{Na}$ tional Renewable Energy Laboratory, the U.S. Department of Energy, the National Science Foundation, and the Air Force Research Laboratory.

\section{References}

1. Basic Research Needs for Solar Energy Utilization: Report on the Basic Energy Sciences Workshop on Solar Energy Utilization, April 18-21, 2005 (Office of Science, U.S. Department of Energy, 2005). 2. Nuclear Energy Data, Edition 2006 (OECD Publishing, Paris, 2006)

3. The Solarbuzz Web site at www.solarbuzz.com maintains up-to-date photovoltaic panel and power cost information.

4. P.D. Maycock, PV News 24 (3) (March 2005). 5. Our Solar Power Future: The U.S. Photovoltaics Industry Roadmap through 2030 and Beyond (SEIA, Washington, DC, 2004).

6. Energy for the Future: Renewable Sources of Energy, White Paper for a Community Strategy and Action Plan (European Commission, 1997).

7. Green Paper: Towards a European Strategy for the Security of Energy Supply (European Commission, 2000).

8. Advanced Energy Initiative (White House National Economic Council, February 2006).

9. T. Surek, J. Cryst. Growth 275 (2005) p. 292.

10. M.A. Green, in Proc. 15th Int. Photovoltaic Sci. \& Eng. Conf. (PVSEC-15) (Shanghai, October 10-15, 2005) p. 7.

11. MRS Bull. 30 (1) (2005).

12. M.A. Green, High-Efficiency Silicon Solar Cells (Trans Tech, Aedermannsdorf, Switzerland, 1987). 13. W. Shockley and H.J. Queisser, J. Appl. Phys. 32 (1961) p. 510.

14. M.A. Green, K. Emery, D.L. King, Y. Hisikawa, and W. Warta, Prog. Photovoltaics: Res. Appl. 15 (2007) p. 35.

15. R.M. Swanson, Prog. Photovoltaics: Res. Appl. 14 (2006) p. 443.

WWW.mis. ORg 


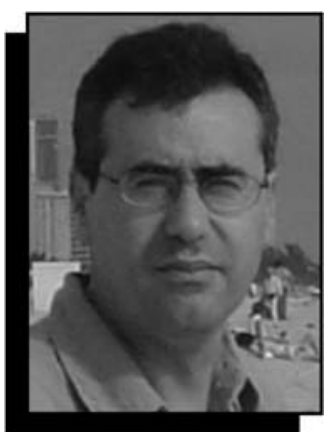

Abdelilah Slaoui

Abdelilah Slaoui, Guest Editor for this issue of MRS Bulletin, is a CNRS research director at Institut d'Electronique du Solide et des Systèmes (InESS) in Strasbourg, France.

He holds BS (1980) and MS (1982) degrees in fundamental physics from the Université Louis Pasteur. He received his $\mathrm{PhD}$ degree in semiconductor physics in 1984 at Laboratory PHASE, where he focused on laser crystallization of implanted silicon for solar cells.

Thereafter, Slaoui continued his work as a postdoctoral fellow on gas-immersion laser doping and oxidation of silicon, laser-induced ablation of materials, and laser-induced crystallization of $\mathrm{Si}$, SiGe, and $\mathrm{SiC}$.

Slaoui joined Centre National de la Recherché Scientifique (CNRS) in 1986 as a research fellow. He is currently head of the photovoltaic group at InESS-CNRSULP (Strasbourg), dealing with bulk and thin-film silicon solar cells as nanomaterials for photovoltaics.

Slaoui has participated in and initiated numerous projects related to silicon-based materials for solar cells. He has authored or co-authored more than 120 papers and four articles in

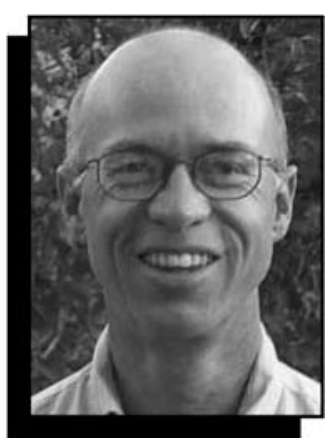

Reuben T. Collins

specialized books. Slaoui co-organized five symposia dealing with materials for photovoltaics in addition to a workshop on materials for energy (Nice, 2004), a workshop on photovoltaic materials (Shanghai, 2005), and a symposium on advanced materials for energy (Beijing, 2006). He was co-chair of the European MRS 2006 conference in Nice, France. Slaoui has also served as an expert for the European Commission. He is currently vice president of the European Materials Research Society and a member of the European Materials Forum.

Slaoui can be reached at InESS-CNRS, 23 rue du loess, F-67037

Strasbourg, France; tel. 33-388-106-328, fax 33-338-106-335, and e-mail slaoui@ iness. c-strasbourg.fr.

Reuben T. Collins, Guest Editor for this issue of MRS Bulletin, is a professor of physics and director of the Center for Solar and Electronic Materials at the Colorado School of Mines.

He received a BA degree in physics and mathematics from the University of Northern Iowa in 1979, and MS and $\mathrm{PhD}$ degrees in applied physics from

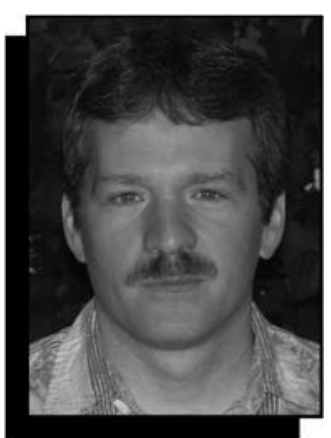

Joseph D. Beach

the California Institute of Technology in 1980 and 1985, respectively. He held positions as research staff member, manager of III-V epitaxy, and technical consultant to the vice president of services, applications, and solutions at the IBM T.J. Watson Research Center before joining the Colorado School of Mines in 1994.

Collins' research interests include photovoltaics, novel lightemitting materials and devices, microelectronics, silicon-compatible optoelectronics, fabrication and properties of nanostructures, and scanning probe microscopy. He has authored or co-authored more than 95 publications, is a co-inventor on three patents, and is a member of the American Physical Society, the Materials Research Society, and the American Society for Engineering

Educators.

Collins can be reached at the Colorado School of Mines, Physics Department, 466 Meyer Hall, Golden, CO 80401 USA; tel. 303-273-3851, fax 303-273-3919, and e-mail rtcollin@mines.edu.

Joseph D. Beach is a research assistant professor in the physics department at the

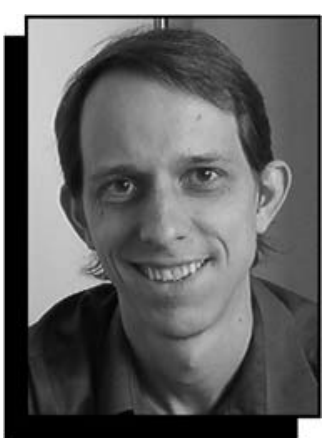

Guy Beaucarne

Colorado School of Mines and one of the founders of the recently formed company PrimeStar Solar. He received his PhD degree in applied physics from the Colorado School of Mines.

Beach has a strong interest in sustainable energy technologies. He is currently investigating ways to improve the performance of $\mathrm{CdTe}$ photovoltaic cells.

Beach can be reached at Colorado School of Mines, Physics Department, Golden, CO 80401 USA; tel. 303-384-2176 and e-mail jbeach@mines.edu.

Guy Beaucarne is head of the Solar Cell Technology group at the Interuniversity MicroElectronics Center (IMEC) in Leuven, Belgium. He received a degree in electromechanical engineering in 1995 from the Catholic University of Leuven. Beaucarne did his $\mathrm{PhD}$ degree research in the field of thin-film silicon solar cells at IMEC and obtained his $\mathrm{PhD}$ degree from the Catholic University of Leuven in 2000.

In 2001, he was a postdoctoral researcher at the University of New South Wales in Sydney, Australia, where he worked on third-generation photovoltaics. He then joined the company Pacific Solar in

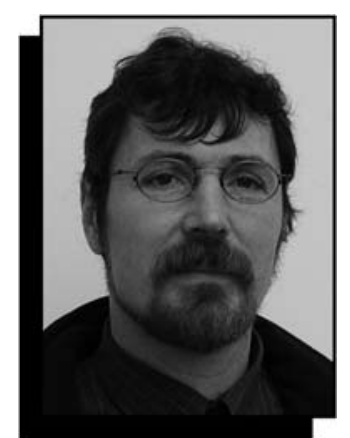

Reinhard Carius

Sydney and contributed to the development of a new crystalline siliconon-glass photovoltaic technology.

In February 2003, Beaucarne returned to IMEC in Belgium, where he supervises all inorganic solar cell activities.

Beaucarne can be reached at IMEC, Solar and Organic Technologies Department, Solar Cell Technology Group, Kapeldreef 75, B-3001, Leuven, Belgium; tel. 32-16-281080, fax 32-16-28 1097, and e-mail guy.beaucarne@ imec.be.

Reinhard Carius heads a group for characterization of materials for thin-film semiconductors in the Institute of Photovoltaics at Forschungszentrum Jülich.

He received his degree in physics in 1981 from the University of Marburg, Germany. He did his $\mathrm{PhD}$ degree research in the field of transport and recombination in amorphous silicon and obtained his $\mathrm{PhD}$ degree from the University of Marburg. In 1987, he joined Forschungszentrum Jülich, where he established a lab for optical spectroscopy and characterization of semiconductors in the Institute for Thin Film and 
Ion Technology. His current research activities are in thin-film semiconductors, with a focus on microcrystalline silicon and related alloys, and photon management in thin-film solar cells.

He has authored or co-authored more than 130 reviewed papers and was active as a symposium organizer at the 2004 and 2005 MRS Spring Meetings.

Carius can be reached at Forschungszentrum Jülich, IPV, 52425 Jülich, Germany; tel. 49-2461-614508, fax 49-2461-618203, and e-mail r.carius@ fz-juelich.de.

Frank Dimroth is head of the III-V solar cells and epitaxy group at Fraunhofer ISE in Freiburg, Germany.

He received his diploma in physics from the University of Zurich in 1996 and his PhD degree from the University of Konstanz in 2000. After a postdoctoral post at the University of Utah, he returned to Fraunhofer ISE and became a research staff member.

Dimroth's main interests are the epitaxial growth of arsenides, phosphides, and antimonides for nextgeneration multijunction solar cells. He has performed applied research in the fields of space and concentrator photovoltaics for electricity and hydrogen production.

Dimroth can be reached at Fraunhofer ISE, Heidenhofstr. 2, D-79110 Freiburg,

Germany; tel. 49-761-45885258, e-mail frank.dimroth@ ise.fraunhofer.de, and URL www.III-V.de.

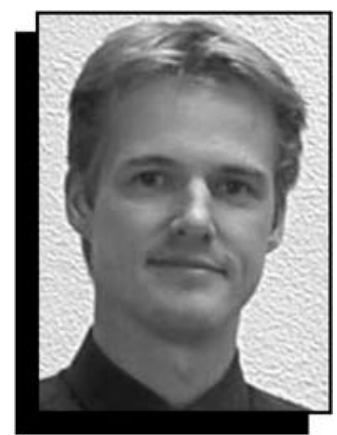

Frank Dimroth

Elvira Fortunato is an associate professor in the Materials Science Department at the New University of Lisbon and has been director of the Materials Research Centre (CENIMAT) since 1998.

She graduated in materials science from $\mathrm{New}$ University of Lisbon. Fortunato received her $\mathrm{PhD}$ degree from New University of Lisbon in 1995 and her Aggregation (teaching certificate) in 2005.

Fortunato pioneered European research on thin-film transistors based on oxide semiconductors, proving the capability to use oxide materials as true semiconductors. Her recent accomplishments include the first ZnO-based transparent thin-film transistor (TTFT) deposited at room temperature by $\mathrm{rf}$ magnetron sputtering with high field-effect mobility. Fortunato's current interests are in the design, fabrication, conduction transport mechanisms, and characterization of amorphous multicomponent oxide-based TTFTs.

Fortunato can be reached at Departamento de Ciência dos Materiais, Faculdade de Ciências e Tecnologia da Universidade Nova de Lisboa, Campus da FCT, 2829-516 Caparica,

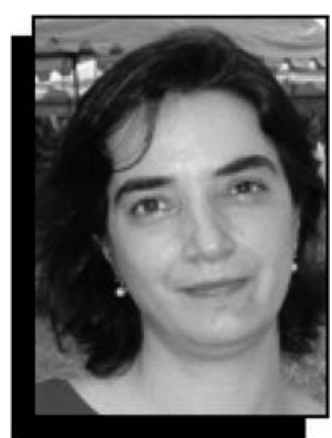

Elvira Fortunato

Portugal; tel. 351-21-2948562, fax 351-21-2948558, and e-mail elvira.fortunato@ fct.unl.pt.

David Ginley is a group manager in process technology and advanced concepts at the National Renewable Energy Laboratory, leading activities in the applications of nanotechnology, organic electronics, transition metal oxides (ferroelectric materials, rechargeable Li batteries, and transparent conductors), and inkjet printing. He is an adjunct professor of physics at the University of Colorado at Boulder and of materials science at the Colorado School of Mines.

Ginley graduated from the Colorado School of Mines with a BS degree in mineral engineering chemistry and received a $\mathrm{PhD}$ degree from MIT in inorganic chemistry. His work focuses on the development and basic science of high-quality materials (transparent conducting oxides, ferroelectric materials, organic materials, and nanomaterials) and the development of next-generation process technology for materials and device development (combinatorial methods, direct-write materials, composite materials, and nonvacuum processing).

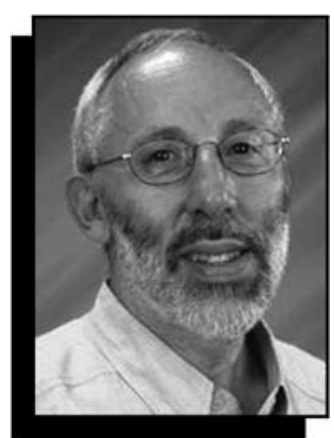

David Ginley

Ginley is a fellow of the Electrochemical Society and active in the Materials Research Society and IEEE. He has published more than 320 papers and holds 24 patents. He has been honored with a Department of Energy Award for Sustained Research in Superconducting Materials, and R\&D 100 awards for novel chemical etches, nanoparticle technology, ferroelectric frequency-agile electronics, and alumina-based nanofibers. He also has received two Federal Laboratory Consortium for Technology Transfer awards.

Ginley can be reached by e-mail at david_ginley@nrel.gov.

\section{Hideo Hosono is a} professor in the Frontier Collaborative Research Center and the Materials and Structures Laboratory at Tokyo Institute of Technology in Japan.

He received both his BEng and DEng degrees in applied chemistry at Tokyo Metropolitan University. Afterward, Hosono was an associate professor at Nagoya Institute of Technology and the Institute of Molecular Science, and became a professor at Tokyo Tech in 1999.

That same year, he was named director of the ERATO Hosano Transparent Electro-

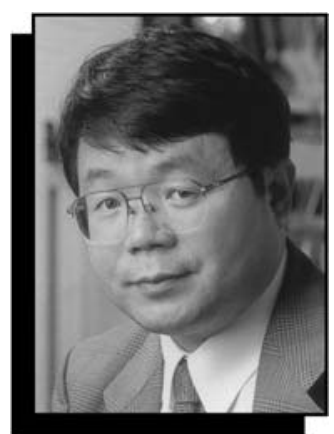

Hideo Hosono

Active Material project (1999-2004), sponsored by the Japan Science and Technology (JST) Agency. He currently is leading the JST project ERATO-SORST. He also leads the MEXT COE-21 program,

"Nanomaterial Cultivation for Industrial Collaboration," for the

Materials Group at

Tokyo Tech.

Hosono has published close to 600 original papers and holds approximately 20 PCT patents. His current research explores novel electroactive transparent oxides and their device applications.

Hosono can be reached at Tokyo Institute of Technology, Mail Box R3-1, Materials and Structures Laboratory, Nagatsuta 4259, Midori, Yokohama 226-8503, Japan; tel. 81-45-9245359, fax 81-45-924-5339, and e-mail hosono@ msl.titech.ac.jp.

Sarah Kurtz is a principal scientist at the National Renewable

Energy Laboratory (NREL) in Golden,

Colorado.

She received her $\mathrm{PhD}$ degree in chemical physics from Harvard University in 1985 and has worked at NREL since.

Her main research interests include epitaxial growth, measurement, 


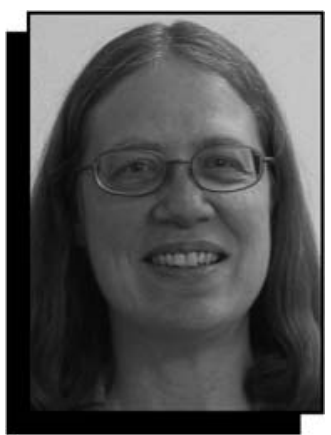

Sarah Kurtz

and modeling of solar cells. She works to support the development and growth of the concentrator industry in particular and of renewable energy in general.

Kurtz can be reached at the National Renewable Energy Laboratory, 1617 Cole Blvd., Golden, CO 80401 USA; tel. 303-384-6475 and e-mail sarah_kurtz@nrel.gov.

Antonio Luque is a full professor of electronic technology at the Polytechnic University of Madrid, where he has been since 1970. He received his DrEng degree in telecommunication in 1969. Luque has also led the Instituto de Energía Solar, which he founded in 1979.

His research activities are mainly devoted to the photovoltaic conversion of solar energy; he invented the bifacial cell in 1976. This cell was fabricated by Isofotón, a company Luque created in 1982 that today is active in more than 50 countries. More recently, he proposed the new intermediate-band solar cell and is working to demonstrate this concept experimentally.

Luque received the Torres Quevedo National Prize for Technology in 1989, the AlexanderEdmond Becquerel Prize in PV research in 1992, the William Cherry

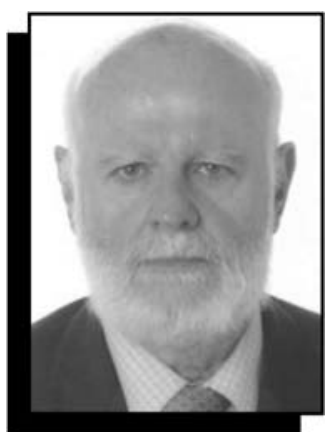

Antonio Luque

Prize for PV research in 2006, the King James I Award for environmental research in 1999, and the National Juan de la Cierva Award for technology transfer. He belongs to the Academies of Engineering of Spain, Russia, and Belarus, is doctor honoris causa at the Universities of Jaén and Carlos III of Madrid, and is an honorary member of

the Ioffe Institute in St. Petersburg. He has published more than 250 scientific papers and several books, and he holds 13 patents.

Luque can be reached at Instituto de Energía Solar, Universidad Politécnica de Madrid, 28040 Madrid, Spain; tel. 34-91336-7229, fax 34-915446341, and e-mail luque@etsit.upm.es.

Antonio Martí is a professor in the Instituto de Energía Solar at the ETS Ingenieros de Telecomunicación, Polytechnic University of Madrid (UPM).

He received his Licenciado en Físicas degree (MS) in 1987 from the Universidad Complutense de Madrid and his $\mathrm{PhD}$ degree from UPM in 1992. He has been with the Instituto de Energía Solar since 1987. In 1988, he became a research assistant, and in 1992 he became a professor.

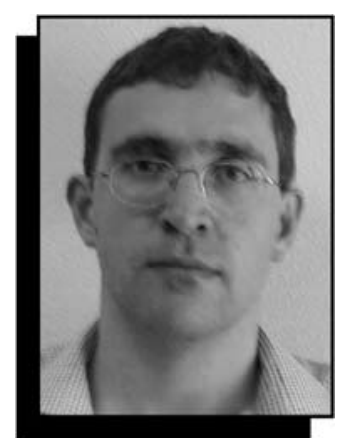

Antonio Martí

Martí received the award for the Best Doctoral Thesis from UPM in 1992 and the Junior Research Award of UPM in 2000. He has published more than 100 papers and conference contributions in the field of photovoltaics.

Martí can be reached at Instituto de Energía Solar-ETSIT, Universidad Politécnica de Madrid, Ciudad Universitaria s/n, 28040 Madrid, Spain; tel. 34-914533551, fax 34-915446341, and e-mail amarti@ etsit.upm.es.

Brian E. McCandless is an associate scientist at the Institute of Energy Conversion at the University of Delaware, where he has been conducting research in thin-film photovoltaics since 1980 . His primary research interest is in relating chemical and kinetic behavior of thinfilm materials to their optoelectronic properties and devices thereof.

McCandless can be reached at the Institute of Energy Conversion, University of Delaware, 451 Wyoming Rd., Newark, DE 19716 USA; tel. 302-831-6240 and e-mail bem@udel.edu.

Arthur J. Nozik has been a senior research fellow at the National Renewable Energy Laboratory (NREL)

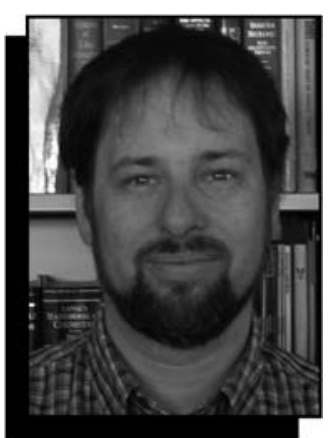

Brian E. McCandless

since 1983 and a professor adjoint in the Chemistry Department at the University of Colorado at Boulder since 1998. $\mathrm{He}$ received his $\mathrm{BChE}$ degree from Cornell University in 1959 and his $\mathrm{PhD}$ degree in physical chemistry from Yale University in 1967.

Before joining NREL, then known as the Solar Energy Research Institute (SERI), in 1978, he conducted research at the Materials Research Center of Allied Chemical Corp. and American Cyanamid. Nozik's research interests include size quantization effects in semiconductor quantum dots and quantum wells and the applications of these nanostructures to solar photon conversion; photogenerated carrier relaxation dynamics in semiconductor structures photoelectrochemistry of semiconductormolecule interfaces; photoelectrochemical energy conversion; photocatalysis; optical, magnetic, and electrical properties of solids; and Mössbauer spectroscopy.

He has published more than 195 papers and book chapters in these fields, holds 11 U.S. patents, and has delivered more than 200 invited talks.

Nozik has served on numerous editorial boards and scientific review and advisory panels. He has received several awards in energy research including the Research Award of the Electrochemical Society in 2002.

He is a fellow of the American Physical Society and the American Association for the Advancement of Science and a member of the American Chemical Society, the Electrochemical Society, the American Association for the Advancement of Science, the Materials Research Society, and the Society of PhotoOptical Instrument Engineers. He was a senior editor of The Journal of Physical Chemistry from 1993 to 2005, and in December 2006, a special Festschrift issue of the journal honoring his 70th birthday was published.

Nozik can be reached at the National Renewable Energy Laboratory, 1617 Cole Blvd., Golden, CO 80401 USA; tel. 303-384-6603, fax 303-384-6655, and e-mail arthur_nozik@nrel.gov.

David C. Paine is a professor of engineering at Brown University. $\mathrm{He}$ earned his $\mathrm{PhD}$ degree in materials science from Stanford University in 1988. Paine's research includes thin-film characterization and processing with particular focus on transparent conducting oxides, sputter and ion-beam deposition, amorphous/ crystalline phase transformations, microstructure evolution, interfaces and interface stability, physical vapor deposition, $x$-ray diffraction, electron microscopy, and, most recently, oxide-based electronics.

Paine can be reached at Brown University, Division of Engineering, 


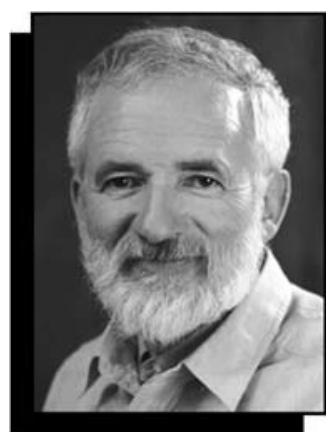

Arthur J. Nozik

Box D, Providence, RI 02912 USA; e-mail david_paine@brown.edu.

Ruud E.I. Schropp is head of the Surfaces, Interfaces, and Devices Program of the Faculty of Science at Utrecht University, the Netherlands.

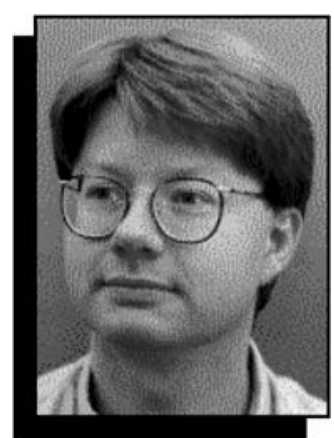

David C. Paine

He received his degree in experimental physics in 1983 from Utrecht University. He did his PhD degree research in the field of thin-film transistor (TFT) research in 1987 at the University of Groningen. Afterward,

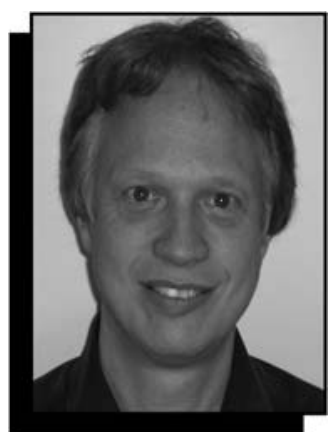

Ruud E.I. Schropp

Schropp worked for two years at Glasstech Solar Inc. in Colorado. In 1989, he joined the faculty at Utrecht University, where he initiated many new projects related to photovoltaics, including projects on thin-film silicon tandem and triple cells, thin-film poly-Si, silicon nitride, nanocrystalline $\mathrm{TiO}_{2}$ dye-sensitized solar cells, and composite $\mathrm{PPV} / \mathrm{TiO}_{2}$ cells. He is co-inventor of the base patent on the temporary superstrate foil approach to low-cost solar cells (in cooperation with Nuon/Helianthos).

Schropp's current research activities are hot-wire CVD (silicon and polymer thin films) and advanced VHF CVD for nextgeneration thin films for photovoltaics and display technology, as well as the development and implementation of rollto-roll CVD processes.
He has authored or co-authored more than 300 papers and was a symposium organizer for the MRS Spring Meeting (1996-1999), the ICANS-21, the 3rd and 4th International Conferences on Hot Wire CVD (Cat-CVD)

Process, and the 2005 and 2006 Plastic

Electronics Conferences.

Schropp can be reached at Utrecht University, Faculty of Science, Surfaces, Interfaces and Devices, PO Box 80.000, 3508 TA Utrecht, the Netherlands; tel. 31-30-2533170, fax 31-30-2543165, and e-mail R.E.I.Schropp@ phys.uu.nl.

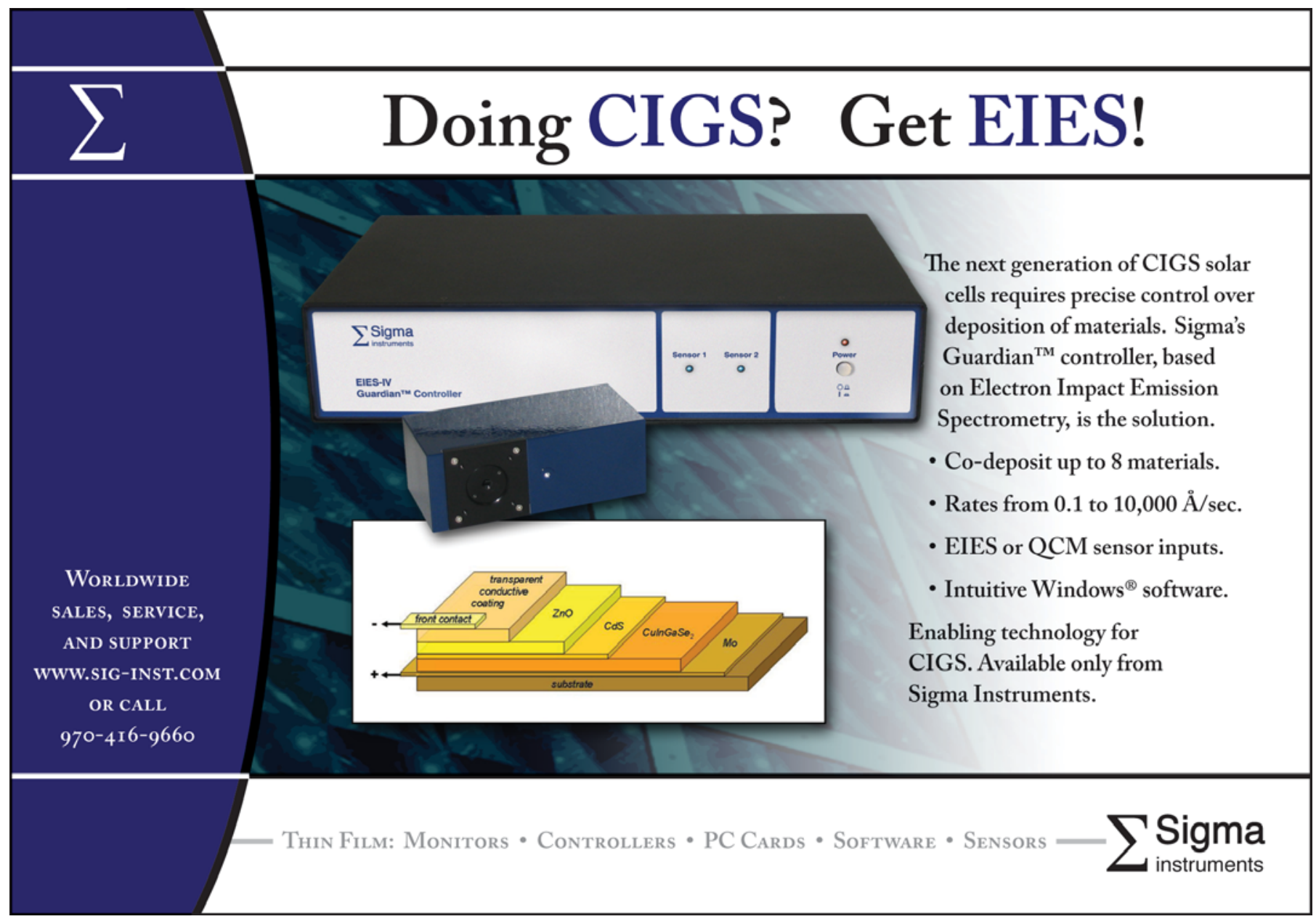

